In Cres. Vol. $3 N^{\circ}$ 1: pp. 153-166, 2012

\title{
RELIGIOSIDAD POPULAR, AGNOSTICISMO, INDIFERENCIA, SINCRETISMO RELIGIOSO Y SECULARISMO EN LA CULTURA URBANA*
}

\author{
POPULAR RELIGIOSITY, AGNOSTICISM, INDIFERENCE, RELIGIOUS \\ SYNCRETISM AND SECULARISM IN THE URBAN CULTURE
}

\section{Juan Roger Rodríguez Ruiz ${ }^{(l)}$}

\section{INTRODUCCIÓN}

Tras la celebración de la V Conferencia General del Episcopado Latinoamericano y del Caribe, realizado en Aparecida, el Santo Padre Benedicto XVI nos dejó un mensaje de esperanza frente a los desafíos de la sociedad contemporánea: «La Iglesia tiene la gran tarea de custodiar y alimentar la fe del pueblo de Dios, y recordar también a los fieles de este continente que, en virtud de su bautismo, están llamados a ser discípulos y misioneros de Jesucristo». ${ }^{1}$

Por otro lado, señala el sacerdote jesuita egipcio-libanés de rito melquita, que «la aparente vitalidad de las iglesias del tercer mundo es equívoca. Según parece, estas nuevas iglesias atravesarán tarde o temprano por las mismas crisis que ha conocido la vieja cristiandad europea». ${ }^{2}$

Ciertamente, la cultura postmoderna y urbana está en expansión en América Latina y se hace sentir principalmente en las capas más instruidas de la población, en los medios de comunicación social y en la política. Se caracteriza por un individualismo y subjetivismo extremados, que se manifiestan en el pluralismo, el relativismo, el secularismo y el permisivismo moral, bajo el pretexto de una autonomía subjetiva que rechaza la normatividad de una verdad fundante y universal. Al mismo tiempo, crece un laicismo militante y anti religioso. ${ }^{3}$ A esta

* Recibido: 03 de febrero del 2012; aceptado: 14 de junio del 2012.

(1) Doctor en Derecho Canónico. Decano de la Facultad de Educación y Humanidades de la Universidad Católica Los Ángeles de Chimbote. Director de la Revista Científica In Crescendo. 
realidad se agrega el fenómeno creciente de la incredulidad, la incertidumbre espiritual en los creyentes y la New Age.

América Latina experimenta problemas como el decrecimiento de la población de la Iglesia, la transmisión intergeneracional de la fe, el crecimiento dinámico de los movimientos no-católicos y un déficit de colaboradores consagrados, pero a la vez presenta grandes oportunidades como el hecho de ser el continente católico más fuerte del mundo (43\%) con la densidad católica más elevada del mundo (84\%), con la experiencia pastoral de más de 500 años y una descomunal y generosa disponibilidad de los laicos. ${ }^{4}$

Al haber iniciado un nuevo milenio Juan Pablo II nos invitaba a interrogarnos con humildad sobre la responsabilidad que tenemos en relación a los males de nuestro tiempo que se encarnan en la llamada cultura de la muerte. A luz de la doctrina de la Iglesia analicemos esta situación y busquemos los cauces para nuestra enmienda, pidiendo humildemente la gracia al Señor.

\section{SITUACIÓN QUE CONSTATAMOS EN LA URBE}

\section{RELIGIOSIDAD POPULAR}

La religión popular latinoamericana sufre, desde hace tiempo, por el divorcio entre élites y pueblo. Eso significa que le falta educación, catequesis y dinamismo, debido a la carencia de una adecuada pastoral. ${ }^{5}$

El fenómeno de la religiosidad popular es en sí mismo una riqueza pastoral. Sin su presencia, algo fundamental faltaría en la tarea de la Iglesia, que es la evangelización. Tengamos en cuenta que toda lejanía puritana de los signos del pueblo, de las costumbres y las tradiciones, puede llevar consigo una pérdida irreparable de aspectos esenciales en la misión de la Iglesia. Cuando se comparan pueblos que tienen semanas santas populares, con otros que carecen de ellas y se encuentra, como resultado, que los jóvenes y los niños de los primeros conocen la historia de la pasión mientras que en los otros se va perdiendo esta memoria; cuando la emigración desde zonas rurales, con amplia tradición popular y cultural, a grandes urbes con anonimato cultural y con una masificación sin comunicación lleva consigo la pérdida de la celebración de la fe y la vuelta a esos lugares, lleva implícito un oasis gratificante. ${ }^{6}$

Ante esta situación es importante alentar una liturgia en total fidelidad al espíritu y a las orientaciones del Concilio Vaticano II, adoptando las formas, signos y acciones propias de las culturas de nuestro continente. Particular atención merece la valorización de la religiosidad popular, que se expresa especial- 
mente en la devoción a nuestra Madre, en peregrinaciones a diversos santuarios y en fiestas religiosas iluminadas por la Palabra de Dios. Debemos empeñarnos en acompañar estas expresiones de nuestra piedad popular, buscando purificarlas y abrirlas a nuevas situaciones, para que el secularismo no se imponga con más fuerza en nuestro pueblo latinoamericano y sea más fácil la inculturación del Evangelio. ${ }^{7}$

La Iglesia, motivada por el espíritu del Documento de Aparecida, hace esfuerzos pastorales orientados hacia el encuentro con Jesucristo, tales como: la animación bíblica de la pastoral, la renovación litúrgica, la entrega abnegada de tantos misioneros comprometidos con la obra evangelizadora y la promoción humana, la renovación pastoral de las parroquias, el florecimiento de las comunidades eclesiales de base, la presencia de los movimientos eclesiales y nuevas comunidades. $^{8}$

Hemos de aprender de la religiosidad popular, que es rica y profunda, en la cual aparece el alma de los pueblos latinoamericanos como precioso tesoro de la Iglesia católica en América Latina. ${ }^{9}$ El Santo Padre invita a promoverla y a protegerla porque «refleja una sed de Dios que solamente los pobres y sencillos pueden conocer». ${ }^{10}$ «La religión del pueblo latinoamericano es expresión de la fe católica. Es un catolicismo popular», ${ }^{11}$ profundamente inculturado, que contiene la dimensión más profunda de la cultura latinoamericana. ${ }^{12}$

\section{EL AGNOSTICISMO}

El agnosticismo reciente es en gran medida antirreligioso, criticando adversamente no sólo el conocimiento que tenemos de Dios, sino también los fundamentos de la fe en Él. Muchos adoptan una combinación del agnosticismo con el ateísmo, más que con una fe irracional y sentimental. Se elimina, personal y sistemáticamente, la idea que se tiene de Dios, del mundo y de la vida. Esta actitud se transforma en indiferencia hacia la religión, en el mejor de los casos como una cuestión inescrutable, y luego en incredulidad. El agnóstico no siempre se abstiene meramente de afirmar o negar la existencia de Dios, sino que se traslada a la vieja posición del ateísmo teórico y deja incluso de creer que Dios exista, de allí que el agnosticismo se encuentra a menudo en combinación con el ateísmo. ${ }^{13}$

La doctrina del agnosticismo por parte del entendimiento cierra al hombre todo camino hacia Dios y, al mismo tiempo, imagina abrírselo a cierto sentimiento del ánimo y de la acción. En realidad, si se suprime el entendimiento, el hombre se irá tras los sentidos exteriores con inclinación mayor aún que la que ya lo arrastra. La inmensa mayoría de los hombres profesan y profesaron siem- 
pre que no se logra jamás el conocimiento de Dios con sólo el sentimiento y la experiencia, sin ninguna guía ni luz de la razón. ${ }^{14}$

Frente a esta situación, Juan Pablo II recordaba que: «Si algunas regiones y algunos ambientes esperan un primer anuncio del Evangelio por todos lados, sin embargo existe la necesidad de que éste se vea renovado. Frecuentemente el conocimiento del cristianismo se da por descontado cuando, en realidad, la Biblia es poco leída y estudiada, la catequesis no siempre profundizada y los sacramentos son poco frecuentados». Añadía el Santo Padre: «De esta forma, en lugar de la auténtica fe se difunde un sentimiento religioso vago y poco comprometedor, que puede convertirse en agnosticismo y ateísmo práctico». ${ }^{15}$

En este sentido, el agnosticismo impone una actitud de no creer en Dios ni en la vida eterna y se muestra intolerante; quiere imponerlo todo y considera que la verdad se decide por mayoría. Es una mentalidad que busca la opinión pública para imponer las ideas y confunde a las personas manipulando argumentos como la democracia, la tolerancia y el diálogo.

\section{INDIFERENCIA RELIGIOSA}

América Latina, a pesar de la homogeneidad del catolicismo, presenta grandes divergencias lingüísticas, étnicas, sociales, políticas y económicas. Además, el catolicismo no crece al ritmo de la población; es decir, mientras el crecimiento poblacional en Latinoamérica es del $77 \%$, el crecimiento de la población católica es del $67 \%$. Esto confirma el decrecimiento que experimenta en los últimos 30 años, ya que en el año 1974 el 89,69\% eran católicos y en el año 2004 se redujo en un $5 \%$, es decir, al $84,72 \%$. $^{16}$

Nuestro continente experimenta una mentalidad secularista que va llevando a las personas hacia el relativismo moral y el indiferentismo religioso. Juan Pablo II señalaba en la Carta Apostólica Tertio millennio adveniente: «¿Cómo callar ante la indiferencia religiosa que lleva a muchos hombres de hoy a vivir como si Dios no existiera o a conformarse con una religión vaga, incapaz de enfrentarse con el problema de la verdad y con el deber de la coherencia?». ${ }^{17}$

Es un indiferentismo de quienes «o rechazan toda religión porque la consideran inútil o nociva para la vida humana y por eso no les interesa, o bien sostienen que todas las religiones son equivalentes y por tanto ninguna puede presentarse como única verdadera». ${ }^{18}$

Por otro lado, el indiferentismo religioso lleva a la pérdida del sentido de Dios y de su santidad, lo cual se traduce en una pérdida del sentido de lo sacro, 
del misterio y de la capacidad de admirarse, como disposiciones humanas que predisponen al diálogo y al encuentro con Dios. Tal indiferentismo lleva casi inevitablemente a una falsa autonomía moral y a un estilo de vida secularista que excluye a Dios. De la pérdida del sentido de Dios se sigue la pérdida del sentido del pecado, el cual tiene su raíz en la conciencia moral del hombre. ${ }^{19}$

En este contexto, el indiferentismo presenta un desafío a la Nueva Evangelización porque suprime la raíz de la relación de la creatura con Dios; es decir, niega todo interés por la religión y con ello el compromiso de la fe, o porque reduce la figura de Cristo a la de un maestro moral o un fundador de religiones entre otras igualmente válidas, negándole el carácter de salvador único, universal y definitivo de los hombres. ${ }^{20}$

De este modo, tanto el indiferentismo como el secularismo minan la moral porque dejan el compromiso humano sin fundamento para su valor ético, y por eso fácilmente caen en el relativismo y el permisivismo que caracterizan a la sociedad de hoy. ${ }^{21}$

\section{SinCRETISMO RELIGIOSO}

Se percibe que un gran número de cristianos se vuelve hacia las religiones orientales, las sectas, la New Age, las iglesias evangélicas, el ocultismo, etcétera. No es de extrañar. Van a buscar en otra parte el alimento que no encuentran en casa; tienen la impresión de que les damos piedras como si fuera pan. La fe cristiana, que en otro tiempo otorgaba sentido a la vida de la gente, resulta para ellos hoy un enigma, restos de un pasado acabado. ${ }^{22}$

Surgen «muchos movimientos pseudorreligiosos de carácter orientalista y aquellos de ocultismo, adivinación y espiritismo que minan la fe y causan desconcierto en las mentes, dando soluciones falsas a los grandes interrogantes del hombre, su destino, su libertad y el sentido de la vida». ${ }^{23}$

En nuestra América se vuelve a los cultos precolombinos. De las religiones precristianas y sus mitologías pasamos a la magia, el ocultismo y el aumento de las sectas satánicas. Como dijo el pensador Umberto Eco: «Cuando los hombres dejan de creer en Dios, no es que no crean en nada, creen en cualquier cosa». Esta religiosidad salvaje, que el cardenal Lehmann la ha definido «teoplasma», es una especie de plastilina religiosa a partir de la cual cada uno fabrica sus dioses a su propio gusto, adaptándose a las necesidades propias. ${ }^{24}$

De nuevo se plantea ante nosotros el desafío en toda su formidable magnitud: ¿cómo anunciar en medio de este magma religioso, en el gran supermerca- 
do del bricolaje religioso, a Jesucristo, el Hijo de Dios hecho hombre, que ha dejado la Iglesia en la tierra como signo y continuadora de su misión entre los hombres? Aquí es donde se requiere toda la audacia del evangelizador, recordando las palabras, hoy más actuales que nunca, de Juan XXIII, en la inauguración del Concilio Vaticano II: «una cosa es el depósito mismo de la fe, o las verdades contenidas en nuestra doctrina, y otra el modo en que éstas se enuncian, conservando, sin embargo idéntico sentido y alcance». ${ }^{25}$

Por otro lado, el diálogo interreligioso surge como un imperativo inaplazable para proponer una firme base de paz y alejar el espectro funesto de las guerras de religión que han bañado de sangre tantos períodos en la historia de la humanidad. Se trata de un diálogo difícil que, sin embargo, nunca puede reemplazar el anuncio explícito de Jesucristo, que es el camino, la verdad y la vida $(J n$ 14,6). Es un diálogo en perpetuo equilibrio entre la búsqueda de caminos de colaboración con otros creyentes, especialmente en la defensa de la vida y en la lucha contra el materialismo asfixiante, y la necesidad de evitar que degenere en sincretismo. Donde todo vale lo mismo, en definitiva nada vale nada. ${ }^{26}$

En cuanto a la New Age, percibimos que en nuestros días surge las multiformes corrientes neoagnósticas, que combinan aforismos, estilos de vida y creencias orientales, y cuya expresión más popular es la poco precisa corriente «New Age». ${ }^{27}$ En la actualidad se ha suscitado el espíritu del milenarismo, de la anticipación de una nueva era, de un cambio radical e instantáneo que pondrá fin al presente estado de las cosas. ${ }^{28}$ Mientras las sectas de corte adventista prevén el fin del milenio, la New Age pregona una edad de oro para toda la humanidad. La New Age es la creencia en el inicio de un mundo cualitativamente diverso y mejor que éste. Este paso evolutivo traerá consigo una iluminación de la conciencia de los hombres. Desvanecerá nuestra percepción fragmentada de la realidad y, supuestamente, veremos al universo entero como es: un todo vivo y único del cual nosotros mismos no somos más que una parte. ${ }^{29}$

El mensaje de la New Age se reviste de un optimismo desbordante y resalta lo positivo, lo fácil y lo inmediato de la transformación que propone. Sin embargo lo más preocupante de la New Age es el relativismo religioso, espiritual y moral, cuya meta final apunta a introducir al hombre un nuevo paradigma, donde hay una forma totalmente diversa de verse a sí mismo y de percibir la realidad. En la New Age Jesucristo pierde su carácter único e irrepetible. Surgen «mesías» y maestros iluminados que se presentan para guiar a la humanidad. Quedando el Cristianismo como un período pasajero de la historia. ${ }^{30}$ 


\section{SECUlARisMo EN LA CULTURA URBANA}

El secularismo hiere a la sociedad urbana actual, marcada, por un lado, por una tradición espiritual y, por otro, por las heridas de la indiferencia y los desafíos del nuevo período sociocultural. ${ }^{31}$

La cultura, en su comprensión más extensa, representa el modo particular con el cual los hombres y los pueblos cultivan su relación con la naturaleza y con sus hermanos, con ellos mismos y con Dios, a fin de lograr una existencia plenamente humana. El patrimonio cultural latinoamericano se ve confrontado con la cultura actual, que presenta luces y sombras. Muchos católicos se encuentran desorientados frente a este cambio cultural. ${ }^{32}$

Benedicto XVI, consciente del cambio de época, cuyo nivel más profundo es el cultural, declara: «Quien excluye a Dios de su horizonte, falsifica el concepto de la realidad y sólo puede terminar en caminos equivocados y con recetas destructivas». ${ }^{33}$

En sintonía con el Santo Padre, los Obispos en Aparecida sostienen que la ciudad se ha convertido en el lugar propio de nuevas culturas que se están gestando e imponiendo. En el mundo urbano, compuesto de ciudades satélites y de barrios periféricos, acontecen complejas transformaciones socioeconómicas, culturales, políticas y religiosas que impactan en todas las dimensiones de la vida. En la ciudad conviven diferentes categorías sociales, tales como las élites económicas, sociales y políticas; la clase media con sus diferentes niveles y la gran multitud de los pobres. En ella coexisten binomios que la desafían cotidianamente: tradición-modernidad, globalidad-particularidad, inclusiónexclusión, personalización-despersonalización, lenguaje secular-lenguaje religioso, homogeneidad-pluralidad y cultura urbana-pluriculturalismo. ${ }^{34}$

Por otro lado, ha aumentado la inquietud por la dimensión cultural del fenómeno tecnológico. Paul Ricoeur hace un diagnóstico implacable del mal de nuestro tiempo y precisa: «Hay una hipertrofia de los medios y una atrofia de los fines. Hay demasiados medios para los escasos y raquíticos fines que se proponen en nuestra sociedad. Tenemos mucha información, sabemos más, pero esta información no nos hace más sabios, ni por tanto, mejores». ${ }^{35}$

Se constata que el mundo asiste a un cambio continuo y vertiginoso que va involucrando una nueva manera de relaciones. Hacia el año 1900, la cantidad de conocimientos disponible para los seres humanos venía doblándose más o menos cada 500 años. Un futurista audaz ha predicho que, para el año 2020, el conocimiento habrá aumentado a una tasa pasmosa, doblándose cada treinta y 
cinco días. Este cambio, alimentado por cantidades de información cada vez mayores, seguirá siendo la característica primordial de la era de la información. ${ }^{36}$

Sin embargo, la Iglesia vive en este mundo usando los medios de comunicación. No puede prescindir de ellos, pues su misión primera y esencial es comunicar la Buena Noticia. Al respecto Pablo VI decía que: «La Iglesia se sentiría culpable ante Dios si no empleara esos poderosos medios que la inteligencia humana perfecciona más». ${ }^{37}$

En este contexto el secularismo tiende a presentarse como una victoria gloriosa del hombre que se va independizando o, por otro lado, se presenta como una deformación radical que aleja al hombre de sus raíces religiosas. Esta mentalidad secularizada va impregnándose en la concepción de la naturaleza, del saber, de la cultura, del Estado y de la religión, manifestándose luego en la secularización de la existencia, del culto a la razón y al progreso, y a la religión secular del progreso. ${ }^{38}$

\section{QUÉ HACER DESDE LA FE Y LA ESPERANZA}

Siguiendo la reflexión que Henri Boulad compartió a través de su carta al Santo Padre Benedicto XVI, nos planteamos a continuación, ¿qué hacer como Iglesia frente a esta situación casi dramática? Probablemente nos sintamos dispuestos a reaccionar en una doble perspectiva: minimizando la gravedad de la situación y consolándose con la esperanza que hay un cierto repunte en este continente de la esperanza o, tal vez, apelando a la confianza en el Señor, que la ha sostenido durante veinte siglos y la seguirá sosteniendo en esta nueva crisis. ${ }^{39}$

Es preciso «transformar la cotidianidad», pero desde prácticas donde se valoren las relaciones horizontales de colaboración participativa como las que se dan en innumerables organizaciones intermedias que hoy van conformando más y más el tejido social, oponiéndose con ella a la exclusión y a la discriminación. ${ }^{40}$ No se debe sólo mejorar la relación interpersonal, sino también los modos de integración grupal marcados por la libertad y la diferencia. Y esto en la familia, en el trabajo, en la escuela, en la política, en las instituciones estatales, también en la comunidad eclesial y, en general, en las restantes organizaciones de la sociedad civil. ¿La comunidad eclesial hará suya esta demanda de los tiempos postmodernos? ? $^{41}$

Frente a esta situación dolorosa y real, sin olvidar la promesa consoladora de la esperanza, se ha de tener en cuenta que: 
a) No es sólo apoyándose en el pasado ni recogiendo sus experiencias como se resolverán los problemas de hoy y de mañana, sino sólo mirando decididamente hacia delante, la Iglesia cumplirá su misión de ser «luz del mundo, sal de la tierra y levadura en la masa»; y

b) Si en el mundo, toda operación comercial que constata un déficit o disfunción se reconsidera inmediatamente, se reúne a expertos, intenta recuperarse, se movilizan todas sus energías para superar la crisis. ¿Por qué la Iglesia no hace otro tanto? ¿Por qué no moviliza todas sus fuerzas vivas para un aggiornamento radical? ¿Tal vez, la pereza, dejadez, orgullo, falta de imaginación, de creatividad, quietismo culpable, en la esperanza de que el Señor se las arreglará y que la Iglesia ha conocido otras crisis en el pasado? ${ }^{42}$ Cristo, en el Evangelio, nos pone en guardia: «Los hijos de las tinieblas gestionan mucho mejor sus asuntos que los hijos de la luz» (cf. Lc 16,8).

La Iglesia tiene hoy una necesidad imperiosa y urgente de una triple reforma:

1. Una reforma teológica y catequética para repensar la fe y reformularla de modo coherente para nuestros contemporáneos. Una fe que va desfigurándose, que no da sentido a la existencia, no es más que un adorno, una superestructura inútil que cae por sí misma.

2. Una reforma pastoral para repensar el espíritu de la fraternidad y la oración, para profundizar procesos de formación en la fe y para fortalecer el exigente compromiso de ser apóstoles en la sociedad de hoy. ${ }^{43}$

3. Una reforma espiritual para revitalizar la mística y repensar los sacramentos con vistas a darles una dimensión existencial y articularlos con la vida.

La Iglesia de hoy se muestra demasiado formalista. Se tiene la impresión de que la institución asfixia el carisma y que lo que finalmente cuenta es una estabilidad exterior, una honestidad superficial. ¿No corremos el riesgo de que un día Jesús nos trate de sepulcros blanqueados?

Esto implica una verdadera evangelización según la estimulante prospectiva de la exhortación Evangelii nuntiandi, que es fundamentalmente el anuncio explícito de Jesucristo Redentor del hombre y de su Buena Noticia de salvación. Es, por consiguiente, la comunicación gozosa y plena de esperanza de la revelación de la paternidad de Dios, de su designio de amor, de su reino, que comienza en este mundo y tiene su plenitud en la eternidad. Es también la proclamación 
de que en Cristo y por Cristo nace un hombre renovado en la justicia y en la santidad y que, con hombres nuevos, debe nacer una sociedad nueva, regida por las normas de las bienaventuranzas e inspirada por la caridad, que genera fraternidad y solidaridad.

Benedicto XVI nos anima en este camino y dice: «Este es el momento de abrirse con confianza a la Providencia de Dios, que nunca abandona a su pueblo y que, con la potencia del Espíritu Santo, le guía hacia el cumplimiento de su designio eterno de salvación». Así, alentados por el Señor rememos mar adentro: confiados en su fuerza, animados por su Palabra, fortalecidos por su gracia y unidos como hermanos, consientes de la grandeza de nuestra vocación cristiana. ${ }^{44}$

\section{PROPUESTAS}

La experiencia de Aparecida no es sólo un documento coyuntural. Es una gracia, una efusión del Espíritu, una convocatoria a recomenzar desde Cristo. Es una nueva manifestación del amor misericordioso del Padre, para que nuestros pueblos en Cristo tengan vida plena. Es una invitación, un reto, un impulso para ser lo que todos debemos ser: discípulos y misioneros de Jesucristo. De allí hemos de aprovechar y crear oportunidades para ponernos a la escucha de lo que el Espíritu quiere decir a nuestras iglesias. Asumiendo el documento con espíritu de fe, con apertura de mente y de corazón, es una palabra profética, una buena nueva, un dinamismo evangelizador. ${ }^{45}$

Asumir el proyecto de la Misión Continental propuesto por la Conferencia de Aparecida es una tarea ambiciosa, significa poner la Iglesia Latinoamericana y Caribeña en estado de misión. Esto exige una inversión del sistema eclesiástico, pues todo debe orientarse hacia la misión. ${ }^{46}$ Solamente una auténtica conversión a nivel personal, comunitario y pastoral, un cambio de mentalidad y comportamiento, movida por el Espíritu Santo, puede tornar exitosa esta iniciativa de la Iglesia. El camino más seguro es volver a las fuentes del Cristianismo, a Jesucristo, a su enseñanza, a su manera de ser, de vivir, de relacionarse con el Padre, con las personas; a su actuar y asumir su pedagogía; tomar como modelos de inspiración a los grandes santos y santas, mártires y testigos de la fe. ${ }^{47}$

En la dinámica del Documento de Aparecida, nos identificamos con las propuestas del Cardenal Poupard, quien desde allí compartía la alegría de ser discípulos y el privilegio de ser misioneros de Jesucristo, proponiendo cinco puntos de orientación de una pastoral de la cultura en clave transversal, para una auténtica evangelización inculturada: 
1. Frente a la difusión mediatizada de imágenes deformes sobre Dios, el hombre, la mujer, la familia, la vida, se propone la antropología cristiana, nacida de una experiencia de nueva iniciación en la fe. La fuerza del kerygma, la catequesis, la liturgia, la homilía dominical y la comunión, son el cimiento sólido para reformular una cultura cristiana que dé nueva savia a las familias y a las comunidades de fe.

2. Frente a los alejados por ignorancia religiosa, relativismo y secularismo, que alimentan las diferentes formas de sectas, sincretismo e indiferentismo, se propone la experiencia existencial de la "proximidad" y el acompañamiento en pequeñas comunidades de fe que generen una cultura de comunión y arraigo compartida con alegría.

3. Frente a la erosión de la vida cristiana, se propone la presentación atrayente del Misterio de Cristo, Hijo de Dios e Hijo de María. Tanto la devoción popular, como la «via pulchritudinis», son un excelente instrumento pastoral para tocar efectivamente y expresar culturalmente la dimensión de lo inefable en la vida cotidiana de una fe, plenamente acogida, totalmente pensada y fielmente vivida.

4. Frente a las situaciones aplastantes de miseria y desamparo, desigualdad social y pobreza; frente al desempleo y migración de los jóvenes a la violencia, ha de promoverse una cultura de la solidaridad fraterna a todos los niveles de la vida social: familiar, local, de instituciones gubernamentales, públicas y organismos privados. Una cultura de la solidaridad fraterna que afirme que su amor preferencial por los pobres implica: «promover a todos los hombres y a todo el hombre», como lo subraya la encíclica Populorum Progressio. ${ }^{48}$

5. Frente a la avalancha de información mediática y mentalidad virtual que generan confusión, desorientación y uniformidad cultural, se propone una adecuada educación humana y cristiana, que abarque de la familia a la parroquia, así como, de la escuela a la universidad, los centros culturales católicos, como lugares privilegiados, para identificar y proponer nuevos horizontes y lenguajes que toquen la fibra existencial de los latinoamericanos y caribeños en una nueva cultura audiovisual.

En definitiva, vivir y participar de la amistad con Cristo es evangelizar la cultura moderna, impregnando los ambientes de la familia, la educación, la comunicación, la vida pública, los escenarios de migración, de culturas rurales, 
indígenas y afro americanas, y la cultura adveniente en las grandes megápolis, con la experiencia de fe en el Resucitado. ${ }^{49}$

\section{CONCLUSIÓN}

Para que el Evangelio pueda fecundar las culturas de este mundo en plena transformación, un impulso renovado debe venir de todos los componentes de la Iglesia ${ }^{50}$ y para impulsar la transformación de la historia y sus dinamismos, los seguidores de Jesús, alentados por la Virgen María, deben dejarse guiar por el Espíritu, y hacer propia la pasión por el Padre y el Reino, para:

1. Ser una Iglesia viva, fiel y creíble, que se alimenta en la Palabra de Dios y en la Eucaristía.

2. Vivir nuestro ser cristiano con alegría y convicción, como discípulosmisioneros de Jesucristo.

3. Formar comunidades vivas que alimenten la fe e impulsen la acción misionera.

4. Valorar las diversas organizaciones eclesiales en espíritu de comunión.

5. Promover un laicado maduro, corresponsable con la misión de anunciar y hacer visible el Reino de Dios.

6. Acompañar a los jóvenes en su formación y búsqueda de identidad, vocación y misión, renovando nuestra opción por ellos.

7. Trabajar con todas las personas de buena voluntad en la construcción del Reino.

8. Fortalecer con audacia la pastoral de la familia y de la vida.

9. Colaborar en la integración de los pueblos de América Latina y el Caribe.

10. Que este continente de la esperanza sea también el continente del amor, de la vida y de la paz. ${ }^{51}$

\section{NOTAS}

1 Benedicto XVI, «Discurso inaugural de la V Conferencia General del Episcopado latinoamericano y del Caribe», 13 mayo 2007.

2 Henri Boulad, La Iglesia al abismo. Disponible en: http://www.reflexionyliberacion.cl/ articulo/720/la-iglesia-en-el-abismo.html.

3 Cf. Cláudio Hummes, Intervención en Aparecida, 18 mayo 2007. www.aica.org/index2.php? pag $=$ VC_20070516_hummes

4 Cf. Norberto Strotmann, La Iglesia después de Aparecida, 124. Instituto de Teología Pastoral "Fray Martín", Lima, 2008.

5 Cf. CELAM, Documento de Puebla, 455. 
Religiosidad popular, agnosticismo, indiferencia, sincretismo religioso y secularismo...

6 Cf. JULIO RAMOS GUERREIRA, «La religiosidad popular y la acción pastoral de la Iglesia», 159.

7 Cf. Celam, Documento de Santo Domingo, 53.

8 Cf. Celam, Documento de Aparecida, 99.

9 Cf. Benedicto XVI, «Discurso inaugural de la V Conferencia General del Episcopado latinoamericano y del Caribe», 13 mayo 2007.

10 PaBlo VI, Evangelii nuntiandi, 48.

11 Celam, Documento de Puebla, 444.

12 Cf. CELAM, Documento de Aparecida, 258.

13 Cf. Shanahan, E.T. Agnosticismo. Enciclopedia católica/ec.aciprensa.com/a/agnosticismo.htm.

14 Cf. Pío X, Pascendi Dominici gregis, 11.

15 Juan Pablo II, Rezo del Angelus, Castelgandolfo, 27 julio 2003.

16 Cf. Norberto Strotmann, La Iglesia después de Aparecida, 67-96. Instituto de Teología Pastoral "Fray Martín”, Lima, 2008.

17 JuAn PABLo II, Tertio millennio adveniente, 36.

18 Celam, Documento de Santo Domingo, 153.

19 Cf. Lineamenta, 19.

20 Cf. Celam, Documento de Santo Domingo, 153.

21 Cf. RIVERA CARRERA, N. La cultura de muerte: agnosticismo funcional y secularismo. Biblioteca electrónica cristiana. BEC- VE Multimedios. http:// multimedios.org/docs/d001076/.

22 Cf. Henri Boulad, La Iglesia en el abismo, 2009. La Iglesia al abismo. Carta personal de Henri Boulad, SJ, a Benedicto XVI, en www.conspiratio.com.mx/conspiratioo/?p=346.

23 Celam, Documento de Puebla, 155.

24 Cf. Paul Poupard, Siete grandes desafios al evangelizar. Disponible en: www.corazones.org/ diccionario/evangelizar_desafios.htm.

25 Cf. Ibidem.

26 Cf. Ibidem.

27 Cf. Consejo Pontificio de la Cultura- Consejo Pontificio para el Dialogo INTERRELIGIOSO. Jesucristo, portador del agua de la vida. Una reflexión cristiana sobre la "Nueva Era”. Disponible en: http://www.vatican.va/roman_curia/pontifical_councils/interelg/ documents/rc_pc_interelg_doc_20030203_new-age_sp.html

28 Cf. NORBERTO RIVERA, N. Instrucción pastoral sobre el New Age, 7 enero 1996, 5.

29 Cf. RIVERA CARRERA, N. La cultura de muerte: agnosticismo funcional y secularismo. Biblioteca electrónica cristiana. BEC- VE Multimedios. http:// multimedios.org/docs/d001076/.

30 Cf. Ibidem, pp.27-30.

31 Juan Pablo II, Audiencia a la delegación de Obispos de la República Checa en visita ad Limina, 15 septiembre 1998.

32 Cf. Felipe Arizmendi Esquivel, Ejercicios espirituales en base al documento de Aparecida. Disponible en http://issuu.com/encristografica/docs/aparecida-ejercicios.

33 Benedicto XVI, «Discurso inaugural de la V Conferencia General del Episcopado latinoamericano y del Caribe», 13 mayo 2007.

34 Cf. Celam, Documento de Aparecida, 510-512.

35 Citado por el Cardenal Paul Poupard en, Siete grandes desafios al evangelizar. Disponible en www.corazones.org/diccionario/evangelizar_desafios.htm.

36 Cf. Dave Kahale, Los 6 sombreros del vendedor exitoso, 57. Editorial Norma, Colombia, 2005.

37 PABLO VI, Exhortación Apostólica, Evangelii nuntiandi, 45.

38 Cf. JosÉ Luis IDÍGORAs, La religión, 337-372.

39 Cf. Henri Boulad, La Iglesia en el abismo, 2009. Disponible en: http://www.reflexiony liberacion.cl/articulo/720/la-iglesia-en-el-abismo.html. 
40 Cf. TRIGo, «Horizonte de las comunidades de solidaridad desde la perspectiva de fe-justicia», Revista Christus, año LXIV, 714, setiembre-octubre 1999, 48.

41 Cf. JoRge R. SEIBOLD, «Pastoral comunitaria urbana: Desafíos, propuestas, tensiones», 15.

42 Cf. Henri Boulad, La Iglesia en el abismo, 2009. Disponible en: http://www.reflexiony liberacion.cl/articulo/720/la-iglesia-en-el-abismo.html.

43 Cf. Celam, Documento de Aparecida, 308.

44 Cf. Jorge Urosa Sabino, Homilía en la Misa de envío para la Misión Continental en Caracas, 7 febrero 2010.

45 Cf. FeliPe ARIZMEndi EsQuivel, Ejercicios espirituales en base al documento de Aparecida. Disponible en http://issuu.com/encristografica/docs/aparecida-ejercicios.

46 Cf. JosÉ CoBlin, «El proyecto de Aparecida», in Revista Spiritus, 48.4, diciembre 2007, 114.

47 Cf. Carlos Raimundo Rockembach, La pedagogía de Jesús, un camino para la misión continental. Disponible en: http://www.google.com.pe/search?q=Carlos + Raimundo + Rockenbach, $+\mathrm{La}+$ pedagog \% C3\% ADa + de + Jes \% C3\% BAs\&hl $=$ es\&sa $=$ X\&ei $=$ z3naT nB42y8QSj5KWEBA\&ved $=0$ CAsQ6wY\&biw $=1342 \& b i h=604$. Cf. Podríamos citar una lista interminable de nombres de misioneros y misioneras inspiradores para nuestro discipulado misionero, pero bástenos señalar a tres de nuestros tiempos, además de San Pablo, San Juan Crisóstomo, San Francisco de Asís, que son inspiración y modelo de discípulos misioneros: Don Helder Cámara, Mons. Oscar Romero y Madre Teresa de Calcuta.

48 Cf. PABlo VI, Encíclica Populorum Progressio, 44.

49 Cf. PAUl POUPARD, Intervención en Aparecida, 17 mayo 2007. Disponible en: http://www.zenit.org/article-23641?1 = spanish

50 Cf. Juan Pablo II, Discurso a los Miembros del Consejo Pontificio para la Cultura. El Evangelio ha de fecundar todas las culturas.

51 Cf. Felipe ArizMEndi Esquivel, Ejercicios espirituales en base al documento de Aparecida. Disponible en http://issuu.com/encristografica/docs/aparecida-ejercicios. 